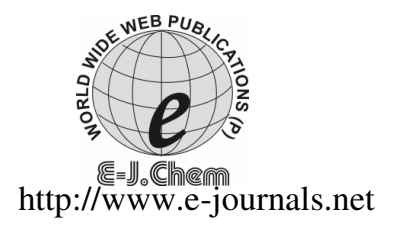

ISSN: 0973-4945; CODEN ECJHAO

E-Journal of Chemistry

2012, 9(1), 63-74

\title{
Platinum Nanoparticles Loaded on Activated Carbon as Novel Adsorbent for the Removal of Congo Red
}

\author{
M. GHAEDI*, S. J. HOSSAINI and S. RAMEZANI ${ }^{\S}$ \\ *Chemistry Department, Yasouj University, Yasouj 75914-353, Iran \\ ${ }^{\S}$ Chemistry Department, Islamic Azad University, Gachsaran Branch, Iran \\ Chemistry Department, Shiraz University, Shiraz, Iran \\ m_ghaedi@mail.yu.ac.ir
}

Received 14 April 2011; Accepted 2 July 2011

\begin{abstract}
Platinum nanoparticles loaded on activated carbon as novel adsorbent was successfully applied for efficient removal of congo red. The influences of effective parameters including contact time, $\mathrm{pH}$ and temperature, amount of adsorbents and concentration of initial dye on the efficiency of removal of congo red from aqueous solution were investigated. Adsorption experiments indicate that the extent of adsorption is strongly dependent on $\mathrm{pH}$ of solution. Thermodynamic parameters like Free energy of adsorption, enthalpy and entropy changes were calculated to know the nature of adsorption. The calculated values of free energy of adsorption (negative value) indicate that the adsorption process is spontaneous. The estimated values of enthalpy and entropy both show the positive sign, which indicate that the adsorption process is endothermic and the dye molecules are organized on the adsorbent surface in more randomly fashion than in solution. Fitting experimental data to different kinetic models including first order, pseudo second order and Elovich and intraparticle diffusion models shows that the rate of dye adsorption follows pseudo second order model and involvement of intera- particle diffusion mechanism.
\end{abstract}

Keywords: Adsorption, Congo red, Platinum nanoparticle loaded on activated carbon, Adsorption isotherm, Thermodynamics and Kinetic of adsorption

\section{Introduction}

Dye wastewater is commonly characterized as high in salt and organic content and low in biodegradation potential ${ }^{1}$. Wastewater containing dyes may be toxic, carcinogenic and even mutagenic and this poses a serious hazard to aquatic living organisms ${ }^{2,3}$. Anionic dyes are the most problematic because of their bright color, water soluble reactive and acidic properties. Many studies has been carried out on adsorption of organic cationic dyes by clay 
minerals ${ }^{4,5}$. In most cases, the adsorption capacity for acidic dyes is much lower than for basic dyes, due to weak interactions between the negatively charged surface on clay minerals and anionic charges on the dyes. The removal of colour from different effluents due to the difficulty in treating such wastewaters by conventional treatment methods is a major problem.

Congo red (CR) or 1-naphthalenesulfonic acid, 3,3'-(4,4'-biphenylenebis (azo)) bis (4-amino-) disodium salt is a benzidine-based anionic diazo dye (Figure 1$)^{6}$. This anionic dye can be metabolised to benzidine, a known human carcinogen ${ }^{7}$. Effluent containing CR is largely produced from textiles, printing, dyeing, paper, and plastic industries $e t c^{8}$. Since the dye is generally present in sodium salt form giving it very good water solubility the treatment of contaminated congo red in wastewater is not straightforward. Also, the high stability of its structure makes it difficult to biodegrade and photo degrades. Various physical, chemical and biological methods including adsorption ${ }^{9-11}$, oxidation or ozonation $^{12,13}$, membrane separation ${ }^{14}$, biodegradation ${ }^{15}$, coagulation and flocculation $^{16}$. Adsorption over a surface with highly ionic character is mostly effective and very fast for a dye with opposite ionic character ${ }^{17}$. Adsorption techniques have potential for removing organics from water due to their high efficiency and ability to separate a wide range of chemical compounds ${ }^{18-20}$.

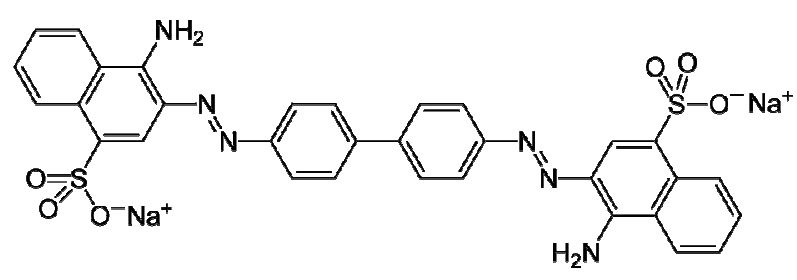

Figure 1 Chemical structure of Congo red

Nanoparticles have very interesting physicochemical properties such as ordered structure high aspect ratio, ultra-light weight, high mechanical strength and high surface area. It is a common behavior that nanoparticles would easily aggregate because of the magnetic property of nanoparticles themselves to form chain-like aggregates ${ }^{21}$.

In the present work, platinum nanoparticle loaded on activated carbon (PtN-AC) was used as novel adsorbent for removal of $\mathrm{CR}$ from aqueous solution. Influences of temperature, $\mathrm{pH}$ of dye solution, effect of adsorbent dose and initial dye concentration were studied under stirred condition. Thermodynamic parameters were calculated to know the nature of adsorption. Different kinetic and isotherm models were applied to understand the mechanism and adsorption parameters of adsorption.

\section{Experimental}

All chemicals including $\mathrm{NaOH}, \mathrm{HCl}$ and other reagent, with the highest purity available are purchased from Merck, Darmstadt, Germany. CR was used as received without any further purification; while its color is stable in the understudy $\mathrm{pH}$. A stock solution of CR was prepared by dissolving its required amount in distilled water and its working solutions with desired concentrations were prepared by successive dilutions of the stock solution. The concentration of the dye was determined at $412 \mathrm{~nm}$ using Jusco UV-Visible spectrophotometer model V-530, pH/Ion meter model-686, thermometer Metrohm, international ASTM sieves and Stirrer model UKA. 


\section{Methods}

To study the effect of important parameters like the $\mathrm{pH}$, contact time, initial dye concentration and temperature on the adsorptive removal of $\mathrm{CR}$, batch experiments were conducted. For each experimental run, $50 \mathrm{~mL}$ of dye solution of known concentration and $\mathrm{pH}$ was mixed completely with optimum value. This mixture was agitated at room temperature controlled shaking water bath at constant speed. Samples were withdrawn at different time intervals (0-15 min), filtrated and analyzed for remaining dye concentration. Effect of $\mathrm{pH}$ on dye removal was studied over a $\mathrm{pH}$ range of 2-7 and further experiments were carried out at $\mathrm{pH} 4$. The initial $\mathrm{pH}$ of the solution was adjusted by addition of dilute aqueous solutions of $\mathrm{HCl}$ or $\mathrm{NaOH}(0.1 \mathrm{M})$. The percentage removal of $\mathrm{CR}$ was calculated using the following equation:

$$
\text { Color removal }(\%)=\left(\left(\mathrm{C}_{0}-\mathrm{C}_{\mathrm{t}}\right) / \mathrm{C}_{0}\right) \times 100 \text {, }
$$

Where $C_{0}$ and $C_{t}\left(\mathrm{mgL}^{-1}\right)$ respectively are initial dye concentration and concentration at time $t$. Kinetics of adsorption was determined by analyzing adsorptive uptake of the dye from aqueous solution at different time intervals. For investigation of adsorption isotherms, different concentrations of $\mathrm{CR}$ in the range $\left(25-300 \mathrm{mgL}^{-1}\right)$ were agitated with $0.02 \mathrm{~g}$ of $\mathrm{PtN}-\mathrm{AC}$ in batch system till the equilibrium was achieved, while the equilibrium adsorption capacity was calculated from the relationship:

$$
\mathrm{q}_{\mathrm{e}}=\left(\mathrm{C}_{\mathrm{o}}-\mathrm{C}_{\mathrm{e}}\right) \mathrm{V} / \mathrm{W} \text {, }
$$

Where $q_{e}\left(\mathrm{mg} \mathrm{g}^{-1}\right)$ is the equilibrium adsorption capacity, $C_{e}$ is the dye concentration at equilibrium, $V(\mathrm{~L})$ is the volume of solution and $W(\mathrm{~g})$ is the weight of adsorbent.

\section{Preparation of PtN-AC}

The carbon-supported $\mathrm{Pt}(\mathrm{Pt} / \mathrm{C})$ was prepared according to literature ${ }^{22}$ as follows: $5 \mathrm{~mL}$ solution $\left(0.0555 \mathrm{~g}\right.$ of $\mathrm{PtCl}_{4}$ salt dissolved in $\mathrm{HCl} 37 \%$ (W/W) double distilled) added into $800 \mathrm{~mL}$ of deionized water and stirred vigorously, followed by the addition of $10 \mathrm{~mL}$ aqueous solution containing $100 \mathrm{mg}$ sodium citrate $\left(\mathrm{Na}_{3} \mathrm{C}_{6} \mathrm{H}_{5} \mathrm{O}_{7} \cdot 2 \mathrm{H}_{2} \mathrm{O}\right)$. One minute later, $10 \mathrm{~mL}$ solution containing $30 \mathrm{mg} \mathrm{NaBH}_{4}$ and $100 \mathrm{mg}$ sodium citrate was added quickly. The mixture was stirred for $1 \mathrm{~h}$ and then $1.2 \mathrm{~g} \mathrm{C}$-active was added and stirring for $48 \mathrm{~h}$ and then standing for $24 \mathrm{~h}$. Finally, the Pt/C was precipitated, washed with distilled water and then dried in an oven at $80{ }^{\circ} \mathrm{C}$.

\section{Determination of the zero point charge $\mathrm{pH}$}

The zero point charge of $\mathrm{pH}\left(\mathrm{pH}_{\mathrm{ZPC}}\right)$ of activated carbon was determined by batch equilibrium technique with 1:1000 and 1:80 of solid liquid ratio in $0.1\left(\mathrm{~mol} \mathrm{~L}^{-1}\right) \mathrm{KNO}_{3}$ solutions. Potassium nitrate was selected as an inert electrolyte. Initial $\mathrm{pH}$ value of $\mathrm{KNO}_{3}$ solution was adjusted to cover range from 2 to 7 by adding $0.1\left(\mathrm{~mol} \mathrm{~L}^{-1}\right) \mathrm{HNO}_{3}$ or $\mathrm{KOH}$. The solutions were allowed to equilibrate for $24 \mathrm{~h}$ in an isothermal shaker at $25 \pm 1{ }^{\circ} \mathrm{C}$. Then the suspensions were filtered through filter paper and $\mathrm{pH}$ values were measured again using ion $\mathrm{pH}$ meter. Again, $\mathrm{PtN}-\mathrm{AC}$ was added to similar solution and stirred for $20 \mathrm{~min}$ and after centrifuge its $\mathrm{pH}$ was recorded. Difference between final $\mathrm{pH}$ and initial $\mathrm{pH}$ of the solution was calculated and plotted versus initial $\mathrm{pH}$ of the $\mathrm{CR}$ solution. The surface of the material is neutral when $\mathrm{pH}=\mathrm{pH}_{\mathrm{zpc}}$. The surface is negatively charged at $\mathrm{pH}$ values greater than $\mathrm{pH}_{\mathrm{ZPC}}$ and positively charged at $\mathrm{pH}$ values lower than $\mathrm{pHpzc}^{23,24}$.

\section{Results and Discussion}

\section{Characterization of adsorbent}

The surface and textural morphology of the nano activated carbon (N-AC) characterized by scanning electron microscopy (SEM) is illustrated in Figure 2. At N-AC, the breadth of the 
tubes was a little broader. There are without the large size particles in the $\mathrm{Pt} / \mathrm{AC}$ which mean the scale of Au particles was at nanometer level. It can be concluded from the SEM analysis that the PtN-AC made is a nanoparticle with relatively large surface area.

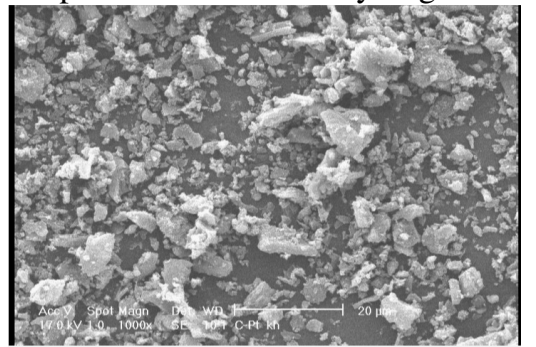

Figure 2. SEM of platinum nanoparticle loaded on activated carbon

\section{Effect of contact time}

The contact time between adsorbates and adsorbent is the most important design parameter that affects the performance of adsorption processes. Therefore, it is necessary that the effect of stirring time in the range of 1-16 min on the efficiency of PtN-AC for removal of CR be investigated at fixed optimum value of $\mathrm{pH}$ and $\mathrm{PtN}-\mathrm{AC}$ dosage using $50 \mathrm{~mL}$ of $25 \mathrm{mg} \mathrm{L}^{-1}$ of CR solution (Figure 3). It was found that more than $80 \%$ removal of dye concentration occurred in the first $4 \mathrm{~min}$, and thereafter the rate of adsorption was found to be slow. The rapid adsorption at the initial contact time is due to the availability of the positively charged surface of adsorbent which lead to fast electrostatic adsorption of the anionic CR at pH 4.0. The later slow rate of $\mathrm{CR}$ adsorption is probably occurred due to the electrostatic repulsion between the adsorbed negatively charged sorbate species onto the surface of adsorbent and the available anionic sorbate species in solution as well as the slow pore diffusion of the solute ion into the bulk of the adsorbent. Therefore, for subsequent work the optimum stirring time about of 9 min was selected for initial CR concentration of $25 \mathrm{mg} \mathrm{L}^{-1}$.

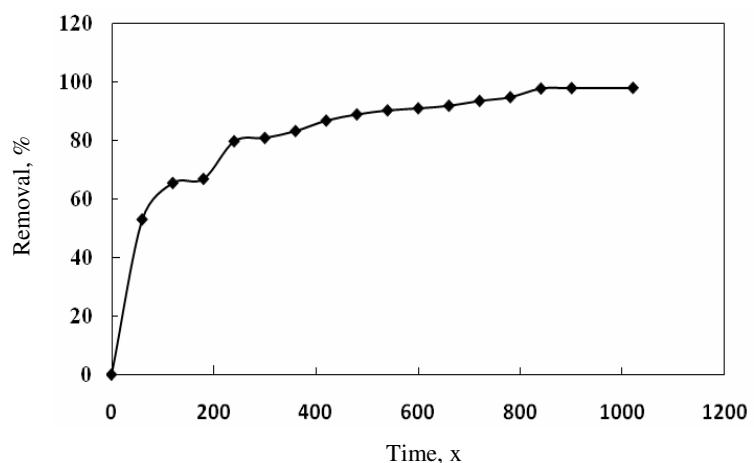

Figure 3. Effect of contact time (S) on CR removal by $0.025 \mathrm{~g}$ of Pt NP-AC in $50 \mathrm{~mL}, \mathrm{pH} 4$ at room temperature and of $15 \mathrm{mg} \mathrm{L}^{-1} \mathrm{CR}$

\section{Effect of $p H$}

The $\mathrm{pH}$ value of the solution is an important controlling parameter in the adsorption process, and the initial $\mathrm{pH}$ of the solution has more influence than the final $\mathrm{pH}$. Effect of $\mathrm{pH}$ on the removal of CR is shown in Figure 4a. As it can be seen increasing $\mathrm{pH}$ from 2 to 7 lead to a significant increase in CR removal. Adsorption of dye on adsorbent occurs either during electrostatic interaction or chemical reaction between the adsorbent and the dye molecule. 
At $\mathrm{pH} 4$ the $\mathrm{H}^{+}$ion concentration in the system increased and the surface of the PtN-AC acquires positive charge by absorbing $\mathrm{H}^{+}$ions. As the adsorbent surface is positively charged at low $\mathrm{pH}$ a significantly high electrostatic attraction exists between the positively charged surface of the PtN-AC and CR (anionic dye molecule) leading to maximum $\mathrm{CR}$ adsorption. By Increasing $\mathrm{pH}$, simultaneously the number of negatively charged sites of adsorbent increase while the number of positively charged sites decreases, that due electrostatic repulsion between dye anions and adsorbent the removal efficiency was decreased. It seems at alkaline $\mathrm{pH}$ number of $\mathrm{OH}^{-}$ions, on the adsorbent surface significantly increased that lead to decrease in removal efficiency.

The point of zero charge $\left(\mathrm{pH}_{\mathrm{ZPC}}\right)$ of $\mathrm{PN}-\mathrm{AC}$ used for the adsorption experiment was determined by using solid to liquid ratio of 1:1000. For this, $0.015 \mathrm{~g}$ of PN-AC was added to $50 \mathrm{~mL}$ of CR solution in the $\mathrm{pH}$ range of 2 to 7 and stirred for $9 \mathrm{~min}$. As it can be seen from plotting difference between final and initial $\mathrm{pH}$ of the solution is versus initial $\mathrm{pH}$ of the solution (Figure $4 \mathrm{~b}$ ) $\mathrm{pH}_{\mathrm{ZPC}}$ for $\mathrm{PtN}-\mathrm{AC}$ was found to be $\mathrm{pH} 2$ and 7.
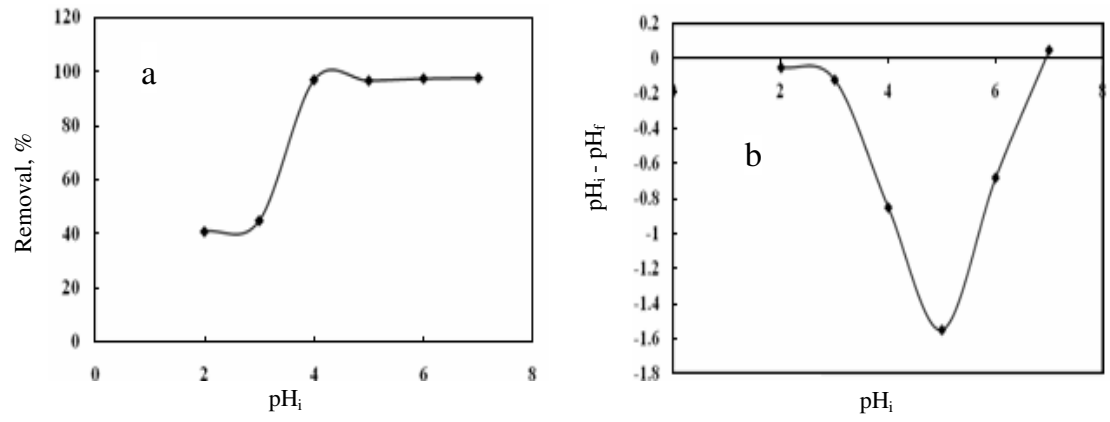

Figure 4(a). Effect of $\mathrm{pH}$ on the removal of $\mathrm{CR}$ by PtNP-AC at room temperature, contact time of $9 \mathrm{~min}$, adsorbent dosage of $0.025 \mathrm{~g}$ in $50 \mathrm{~mL}$ and dye concentration of $15 \mathrm{mg} \mathrm{L}^{-1}$; (b) pHzpc of PtNP-AC

\section{Effect of adsorbent dosage}

The effect of PtN-AC quantity on removal of $\mathrm{CR}$ was investigated in batch experiments by addition of various amount of PN-AC in the range of $0.005-0.03 \mathrm{~g}$ into $50 \mathrm{~mL}$ of $25 \mathrm{mg} \mathrm{L}^{-1}$ of $\mathrm{CR}$ solution at $\mathrm{pH} 4$ for $9 \mathrm{~min}$. As it can be seen from results presented in Figure 5a by increasing the amount of PN-AC dosage up to $0.025 \mathrm{~g}$ the efficiency of removal of CR was increased and further addition of adsorbent has not significant influence on CR removal efficiency. This phenomenon can be attributed to greater surface area and the availability of more adsorption sites by further increasing adsorbent surface.

\section{Effect of initial dye concentration}

The effect of initial concentration of $\mathrm{CR}$ on its removal efficiency using PtN-AC adsorbent in the range of $10-40 \mathrm{mg} \mathrm{g}^{-1}$ was studied and respective results are shown in Figure 6. As it is show, the removal percentage of the CR was found to decrease with the increase in initial dye concentration. This indicates that there exist reductions in immediate solute adsorption, owing to the lack of available active sites required for the high initial concentration of CR. The results show that the percentage removal of dye decreases from 15 to $40 \mathrm{mg} \mathrm{g}^{-1}$. For subsequent analysis the initial concentration of CR was adjust at $15 \mathrm{mg} \mathrm{L}^{-1}$. 


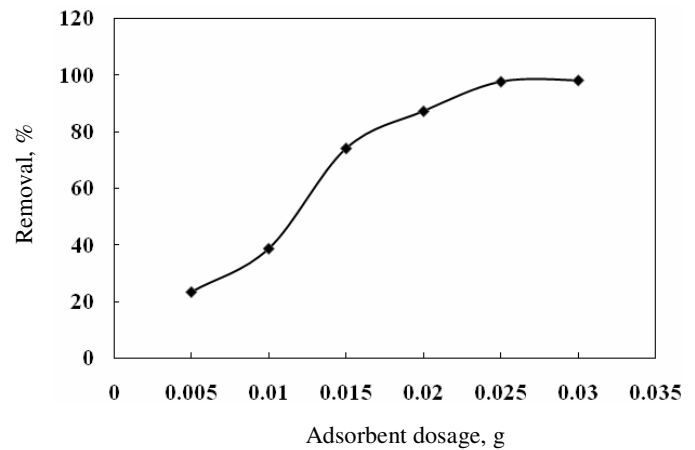

Figure 5. Effect of PtN-AC dosage on CR removal at dye concentration of $15 \mathrm{mg} \mathrm{L}^{-1}$ in $200 \mathrm{~mL}$, at $\mathrm{pH} 4$ and room temperature

\section{Effect of temperature}

The effect of temperature on the adsorption CR onto this new adsorbent is shown in Figure 7. The increase in CR removal efficiency by increasing temperature from 283.15 to $333.15 \mathrm{~K}$, indicate the endothermic nature of adsorption process. Temperature is significantly influence the viscosity of solution and rate of diffusion of the adsorbate molecules across the external boundary layer and in the internal pores of the adsorbent particle. In addition, changing temperature will change the equilibrium capacity of the adsorbent for particular adsorbate. The temperature raising may increase the tendency of de-aggregation and so the uptake of the monomers of CR.

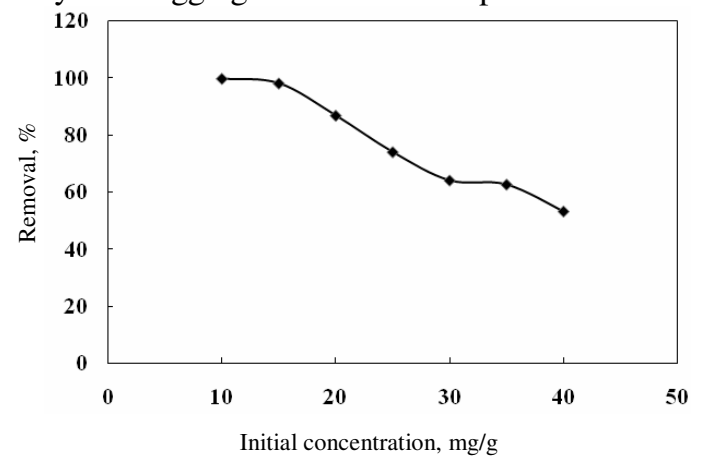

Figure 6. Effect of initial dye concentration on removal of CR at $0.025 \mathrm{~g}$ of PtN-AC in $50 \mathrm{~mL}$, $\mathrm{pH} 4$ and room temperature

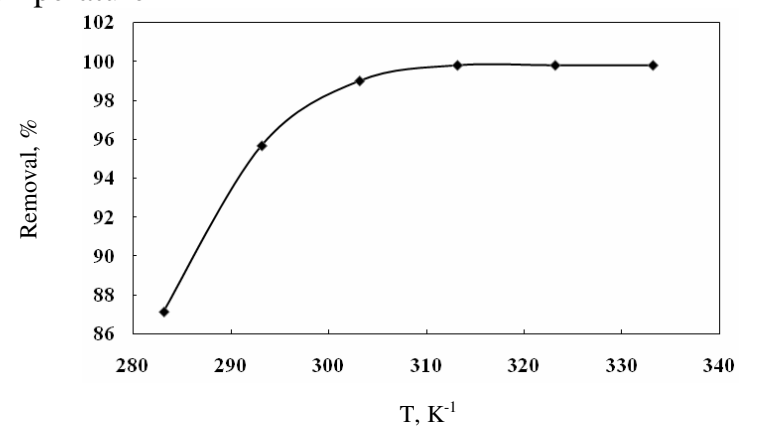

Figure 7. Effect of temperature on removal of $\mathrm{CR}$ at $0.025 \mathrm{~g}$ of PtN-AC in $50 \mathrm{~mL}$, pH 4 and dye concentration of $15 \mathrm{mg} \mathrm{L}^{-1}$ 


\section{Adsorption equilibrium study}

The adsorption isotherm indicates how the adsorption molecules distribute between the liquid phase and the solid phase when the adsorption process reaches an equilibrium state. The analysis of the isotherm data by fitting them to different isotherm models is an important step to find the suitable model ${ }^{25,26}$. Several models including Langmuir Freundlich and Tempkin isotherms have been published in the literature to describe the experimental data of adsorption isotherms. In this work, all models were used to describe the relationship between the amount of dye adsorbed and its equilibrium concentration.

\section{Langmuir isotherm}

The theoretical Langmuir sorption isotherm ${ }^{27}$ is valid for adsorption of a solute from a liquid solution as monolayer adsorption on a surface containing a finite number of identical sites. Langmuir isotherm model assumes uniform energies of adsorption onto the surface without transmigration of adsorbates in the plane of the surface. The linear form of Langmuir isotherm model may be written as:

$$
\mathrm{C}_{\mathrm{e}} / \mathrm{q}_{\mathrm{e}}=1 / \mathrm{k}_{\mathrm{L}} \mathrm{Q}_{\mathrm{m}}+\mathrm{C}_{\mathrm{e}} / \mathrm{Q}_{\mathrm{m}}
$$

Where, $K_{L}$ is the Langmuir adsorption constant $\left(\mathrm{Lmg}^{-1}\right)$ and $Q_{m}$ is the theoretical maximum adsorption capacity $\left(\mathrm{mg} \mathrm{g}^{-1}\right)$. The value of $\mathrm{Q}_{\mathrm{m}}$ and $\mathrm{K}_{\mathrm{L}}$ constant obtained by plotting $C_{e} / q_{e}$ vs. $C_{e}$ and the correlation coefficient of this model is presented in Table 1. It was seen that removal of $\mathrm{CR}$ on PtN-AC was linear over the whole concentration range studies were extremely high correlation coefficients $\left(\mathrm{R}^{2}>0.99\right)$.

Table 1. Isotherm parameters and correlation coefficients calculated by various adsorption models onto $0.025 \mathrm{~g}$ of PtN P-AC in $50 \mathrm{~mL}, \mathrm{pH} 4$ and room temperature.

\begin{tabular}{lcc}
\hline Langmuir- $1:$ & $\mathrm{Q}_{\mathrm{m}}, \mathrm{mg} / \mathrm{g}$ & 43.478 \\
\cline { 2 - 3 } $\mathrm{C}_{\mathrm{e}} / \mathrm{q}_{\mathrm{e}}=\left(1 / \mathrm{K}_{\mathrm{a}} \mathrm{Q}_{\mathrm{m}}\right)+\mathrm{C}_{\mathrm{e}} / \mathrm{Q}_{\mathrm{m}}$ & $\mathrm{K}_{\mathrm{a}}, \mathrm{L} \mathrm{mg}^{-1}$ & 2.3 \\
& $\mathrm{R}^{2}$ & 0.993 \\
\hline Freundlich: & $1 / \mathrm{n}$ & 0.108 \\
$\log \mathrm{q}_{\mathrm{e}}=\log \mathrm{K}_{\mathrm{F}}+(1 / \mathrm{n}) \log \mathrm{C}_{\mathrm{e}}$ & $\mathrm{K}_{\mathrm{F}}, \mathrm{L} / \mathrm{mg}$ & 31.261 \\
& $\mathrm{R}^{2}$ & 0.965 \\
Tempkin: & $\mathrm{B}_{1}$ & 3.288 \\
$\mathrm{q}_{\mathrm{e}}=\mathrm{B}_{1}$ Ln $\mathrm{K}_{\mathrm{T}}+\mathrm{B}_{1} \mathrm{Ln} \mathrm{C}_{\mathrm{e}}$ & $\mathrm{K}_{\mathrm{T}} \times 10^{+5}, \mathrm{~L} / \mathrm{mg}$ & 0.1962242 \\
\hline
\end{tabular}

\section{Freundlich isotherm}

The Freundlich isotherm model is valid for multilayer adsorption ${ }^{28}$. The model applies to adsorption on heterogeneous surfaces with interaction between adsorbed molecules. This isotherm is based on empirical equation applicable for heterogeneous systems and expressed as following:

$$
\mathrm{q}_{\mathrm{e}}=\mathrm{k}_{\mathrm{f}} \mathrm{C}_{\mathrm{e}}^{1 / \mathrm{n}} \mathrm{f}
$$

Where $K_{\mathrm{f}}$ is the Freundlich constant $\left(\mathrm{L} \mathrm{g} \mathrm{g}^{-1}\right)$ related to the bonding energy. $K_{\mathrm{f}}$ can be defined as the adsorption or distribution coefficient and represents the quantity of dye adsorbed onto adsorbent. $1 / \mathrm{n}_{\mathrm{f}}$ is the heterogeneity factor and $\mathrm{n}_{\mathrm{f}}$ is a measure of the deviation from linearity of adsorption, which its value indicates the degree of non-linearity between solution concentration and adsorbed concentration. Value of $n_{f}$ equal to unity show the linearity of adsorption, value lower than unity implies that adsorption process is chemical, while its value higher than unity indicate favorable physical adsorption process. Eq. (4) can be linearized in the logarithmic linear: 


$$
\log \mathrm{q}_{\mathrm{e}}=\log \mathrm{K}_{\mathrm{f}}+1 / \mathrm{n}_{\mathrm{f}} \log \mathrm{C}_{\mathrm{e}}
$$

The value of $K_{\mathrm{f}}$ and the slope of $1 / \mathrm{n}_{\mathrm{f}}$ indicate by plooting $\log \left(q_{e}\right)$ versus $\log \left(C_{e}\right)$ (Table 1$)$. As it can be seen Freundlich is unsuitable model for interpreting whole isotherm interpretation.

\section{Tempkin isotherm}

Tempkin isotherm model contains a factor that explicitly takes into account adsorbing species-adsorbate interactions ${ }^{29}$. The derivation of the tempkin isotherm assumes that the fall in the heat of sorption is linear rather than logarithmic, as implied in the Freundlich equation. The linear form of the Tempkin isotherm equation is represented by the following equation:

$$
\mathrm{q}_{\mathrm{e}}=\mathrm{B}_{1} \ln \mathrm{K}_{\mathrm{T}}+\mathrm{B}_{1} \ln \mathrm{Ce},
$$

Where $\mathrm{B}_{1}=\mathrm{RT} / \mathrm{b}, \mathrm{T}$ is the absolute temperature in Kelvin, $\mathrm{R}$ the universal gas constant $\left(8.314 \mathrm{JK}^{-1} \mathrm{~mol}^{-1}\right), \mathrm{K}_{\mathrm{T}}$ is the equilibrium binding constant and the constant $\mathrm{B}_{1}$ is related to the heat of adsorption $(\mathrm{L} / \mathrm{g})$. Values of $\mathrm{B}_{1}$ and $\mathrm{K}_{\mathrm{T}}$ were calculated from the plot of $\mathrm{q}_{\mathrm{e}}$ against Ln $\mathrm{C}_{\mathrm{e}}$ (Table 1). Low correlation coefficient of this model show it's inapplicably for total isotherm analysis of data.

\section{Kinetic study}

In order to investigate the adsorption processes of CR on the adsorbents, pseudo-first-order, pseudo-second-order, Elovich and intra-particle diffusion kinetic models were studied. The adsorption kinetic data were described by the Lagergren pseudo-first-order model ${ }^{30}$. The Lagergren equation is commonly expresses as follows:

$$
\mathrm{dq}_{\mathrm{t}} / \mathrm{d}_{\mathrm{t}}=\mathrm{k}_{1}\left(\mathrm{q}_{\mathrm{e}}-\mathrm{q}_{\mathrm{t}}\right) \text {, }
$$

Where $q_{e}$ and $q_{t}$ are the adsorption capacity at equilibrium and at time $t$, respectively $\left(\mathrm{mg} \mathrm{g}^{-1}\right), k_{1}$ is the rate constant of pseudo-first-order adsorption $\left(1 \mathrm{~min}^{-1}\right)$. Integrating Eq. (7) for the boundary conditions $t=0$ to $t=t$ and $q_{t}=0$ to $q_{t}=q t$ gives:

$$
\log \left(\mathrm{q}_{\mathrm{e}} / \mathrm{q}_{\mathrm{e}}-\mathrm{q}_{\mathrm{t}}\right)=\mathrm{k}_{1} / 2.303 \mathrm{t} \text {, }
$$

Eq. (8) can be rearranged to obtain the following linear form:

$$
\log \left(\mathrm{q}_{\mathrm{e}}-\mathrm{q}_{\mathrm{t}}\right)=\log \left(\mathrm{q}_{\mathrm{e}}\right)-\mathrm{k}_{1} / 2.303 \mathrm{t} \text {. }
$$

Slope and intercept of plot of $\log \left(q_{e}-q_{t}\right)$ versus $t$ show the value of $k_{1}$ and $q_{e}$, respectively. If the intercept dose not equal $q_{e}$ then the reaction is not likely to be first-order reaction even this plot has high correlation coefficient with the experimental data. The variation in rate should be proportional to the first power of concentration for strict surface adsorption. However, the relationship between initial solute concentration and rate of adsorption will not be linear when pore diffusion limits the adsorption process. Furthermore, the $R^{2}$ are relatively low for most adsorption data (Table 2), which indicates that the adsorption of $\mathrm{CR}$ onto PtN-AC is not a first-order reaction. Therefore, it is necessary that experimental data be fitted to other models. The adsorption kinetic may be described by the pseudo-second order model ${ }^{30}$ which is generally given as following:

$$
\mathrm{dq}_{\mathrm{t}} / \mathrm{d}_{\mathrm{t}}=\mathrm{k}_{2}\left(\mathrm{q}_{\mathrm{e}}-\mathrm{q}_{\mathrm{t}}\right)^{2} \text {. }
$$

Integrating Eq. (10) for the boundary conditions $q_{t}=0$ to $q_{t}=q t$ at $t=0$ to $t=t$ is simplified as can be rearranged and linearized to obtain:

$$
\left(\mathrm{t} / \mathrm{q}_{\mathrm{t}}\right)=1 / \mathrm{k}_{2} \mathrm{q}_{\mathrm{e}}^{2}+1 / \mathrm{q}_{\mathrm{e}}(\mathrm{t}) \text {. }
$$

The second-order rate constants were used to calculate the initial sorption rate, given by the following:

$$
\mathrm{h}=\mathrm{k}_{2} \mathrm{q}_{\mathrm{e}}^{2} \text {. }
$$


Table 2. Adsorption kinetic parameters at different initial Congo red onto $0.025 \mathrm{~g}$ of PtN$\mathrm{AC}$ in $50 \mathrm{~mL}$ at $\mathrm{pH} 4$, room temperature and congo red concentration of $15 \mathrm{mg} \mathrm{L}^{-1}$

\begin{tabular}{ccc}
\hline \multirow{2}{*}{ Model } & & $\begin{array}{c}\text { Initial Congo red } \\
\text { concentration, }\end{array}$ \\
\cline { 3 - 3 } & & $15 \mathrm{mg} \mathrm{L}^{-1}$ \\
\hline \multirow{3}{*}{ First-order kinetic } & $\mathrm{k}_{1} \times 10^{-3}$ & 2.303 \\
& $\mathrm{q}_{\mathrm{e}}(\mathrm{calc})$ & 26.24 \\
& $\mathrm{R}^{2}$ & 0.983 \\
& $\mathrm{k}_{2} \times 10^{-4}$ & 2.216 \\
Second-order kinetic & $\mathrm{q}_{\mathrm{e}}(\mathrm{calc})$ & 52.63 \\
& $\mathrm{R}^{2}$ & 0.998 \\
Intraparticle diffusion & $\mathrm{h}$ & 0.6138 \\
& $\mathrm{~K}_{\text {diff }}$ & 0.883 \\
& $\mathrm{C}$ & 23.37 \\
Elovich & $\mathrm{R}^{2}$ & 0.927 \\
& $\beta$ & 0.122 \\
& $\alpha$ & 3.61 \\
& $\mathrm{R}^{2}$ & 0.981 \\
& $\mathrm{q}_{\mathrm{e}}(\mathrm{exp})$ & 48.81 \\
\hline
\end{tabular}

It was mentioned above that the curve fitting plots of $\log \left(q_{e}-q_{t}\right)$ versus $t$ does not show good results for the entire sorption period, while the plots of t/qt versus $t$ give a straight line, confirming the applicability of the pseudo-second-order equation. Values of $k_{2}$ and equilibrium adsorption capacity $q_{e}$ were calculated from the intercept and slope of the plots of $t / q_{t}$ versus $t$, respectively. At all concentrations and sorbent doses, $R^{2}$ values for pseudosecond-order kinetic model were found to be higher and the calculated $q_{e}$ values are mainly closer to the experimental data. This indicates that the CR-PtN-AC adsorption system obeys the pseudo-second-order kinetic model for the entire sorption period. The Elovich equation is another rate equation based on the adsorption capacity is given as follows ${ }^{31-33}$;

$$
\mathrm{dq}_{\mathrm{t}} / \mathrm{dt}=\alpha \exp \left(-\beta \mathrm{q}_{\mathrm{t}}\right)
$$

Where $\alpha$ is the initial adsorption rate $\left(\mathrm{mg} \mathrm{g}^{-1} \mathrm{~min}^{-1}\right)$ and $\beta$ is the de-sorption constant $\left(\mathrm{gmg}^{-1}\right)$ during any one experiment. It is simplified by assuming $\alpha \beta \gg \mathrm{t}$ and by applying the boundary conditions $\mathrm{q}_{\mathrm{t}}=0$ at $\mathrm{t}=0$ and $\mathrm{q}_{\mathrm{t}}=\mathrm{q}_{\mathrm{t}}$ at $\mathrm{t}=\mathrm{t}$ Eq. (13) rewrite as followed:

$$
\mathrm{q}_{\mathrm{t}}=1 / \beta \ln (\alpha \beta)+1 / \beta \ln (\mathrm{t}) \text {. }
$$

Plot of $\mathrm{q}_{\mathrm{t}}$ versus $\ln (\mathrm{t})$ should yield a linear relationship if the Elovich is applicable with a slope of $(1 / \beta)$ and an intercept of $(1 / \beta) \ln (\alpha \beta)$. The Elovich constants obtained from the slope and the intercept of the straight line which are reported in Table 2 show that the correlation coefficient $\mathrm{R}^{2}$ is 0.976 for this model.

Another alternative method for kinetic evaluation of an adsorption process is intraparticle-diffusion model that is based on the phenomena that dye adsorption on sorbent material take place through four steps: (a) migration of dye molecules from bulk solution to the surface of the adsorbent through bulk diffusion, (b) diffusion of dye molecules through the boundary layer to the surface of the adsorbent via film diffusion; (c) the transport of the dye molecules from the surface to the interior pores of the particle occur through intraparticle-diffusion or pore-diffusion mechanism and (d) the adsorption of dye on the surface of material by chemical reaction via ion-exchange, complexation and/or chelation. If the adsorption experiment is a batch system with rapid stirring, there is a possibility that the 
transport of sorbate from solution into pores (bulk) of the adsorbent is the rate-controlling step. This possibility was tested in terms of a graphical relationship between the amount of dye adsorbed and the square root of time. The intra-particular diffusion is commonly expressed by the following equation ${ }^{34}$ :

$$
\mathrm{q}_{\mathrm{t}}=\mathrm{K}_{\mathrm{dif}} \mathrm{t}^{1 / 2}+\mathrm{C} \text {. }
$$

The values of $\mathrm{K}_{\mathrm{dif}}$ was calculated from the slopes of $\mathrm{q}_{\mathrm{t}}$ versus $\mathrm{t}^{1 / 2}$ where $\mathrm{C}$ is the intercept which is related to the thickness of the boundary layer and their obtained value is reported in Table 2 and $\mathrm{K}_{\text {dif }}\left(\mathrm{mg} \mathrm{g}^{-1} \mathrm{~min}^{-1 / 2}\right)$ is the intraparticle diffusion rate constant. It was reported that if the intraparticle diffusion is the sole rate-limiting step it is essential for the $\mathrm{q}_{\mathrm{t}}$ versus $\mathrm{t}^{1 / 2}$ plots to pass through the origin that means if the value of $\mathrm{C}$ was equal to zero, indicating that the intraparticle diffusion model may be the controlling factor in determining the kinetics of the process. The $\mathrm{R}^{2}$ values given in Table 2 is far from the unity indicating not applicability of this model, which show that the rate-limiting step is not the intraparticle diffusion process, but the intraparticle diffusion model may be the controlling factor in determining the kinetics of the process.

\section{Thermodynamic study}

The thermodynamic constants including free energy change, enthalpy change and entropy change were calculated to evaluate the thermodynamic feasibility and the spontaneous nature of the process. Thermodynamic constants can be obtained from the following equations:

$$
\Delta \mathrm{G}^{\circ}=-\mathrm{RT} \ln \mathrm{K}_{0},
$$

Where $\Delta G^{\circ}$ is the free energy change $\left(\mathrm{kJ} \mathrm{mol}^{-1}\right), R$ is the universal gas constant (8.314 $\mathrm{Jmol}^{-1} \mathrm{~K}^{-1}$ ), $K_{o}$ the thermodynamic equilibrium constant and $T$ is the absolute temperature (K). Values of $K_{0}$ may be calculated from the relation $\ln q_{e} / C_{e} v s . q_{e}$ at different temperatures and extrapolating to zero. As it can be seen from thermodynamic parameters listed in Table 3, negative $\Delta \mathrm{G}^{\circ}$ value indicates that the removal process is spontaneous while the values of $\Delta \mathrm{G}^{\circ}$ decrease with raising the temperature that showing the increase in the feasibility of the adsorption process at higher temperatures. The values of other parameters such as enthalpy change $\left(\Delta H^{\circ}\right)$ and entropy change $\left(\Delta S^{\circ}\right)$, may be determined from Van't Hoff equation:

$$
\operatorname{Ln} K^{\circ}=\Delta S^{\circ} / R-\Delta H^{\circ} / R T \text {. }
$$

Table 3. Thermodynamic parameters for adsorption of Congo red onto $0.025 \mathrm{~g}$ PtNP-AC in $50 \mathrm{~mL}$ at $\mathrm{pH} 4$ at initial dye concentration of $15 \mathrm{mg} \mathrm{L}^{-1}$

\begin{tabular}{ccccccccc}
\hline \multirow{2}{*}{ Adsorbent } & $\begin{array}{c}\mathrm{C}_{0} \\
\mathrm{mg} / \mathrm{L}\end{array}$ & \multirow{2}{*}{ Parameter } & \multicolumn{6}{c}{ Temperature (K) } \\
& & & 283.15 & 293.15 & 303.15 & 313.15 & 323.15 & 333.15 \\
Carbon-Au & 50 & $\mathrm{k}_{\mathrm{c}}$ & 11.99 & 35.868 & 254.64 & 1901.67 & 2576.78 & 2277.33 \\
& & $\Delta \mathrm{G}^{0} \mathrm{~kJ} / \mathrm{mol}$ & -5.85 & -8.72 & -13.96 & -19.66 & -21.10 & -21.41 \\
& & & $\Delta \mathrm{S}^{0}$ & $\Delta \mathrm{H}^{0}$ & $\mathrm{E}_{\mathrm{a}}$ & $\mathrm{S}^{*}$ & $\Delta \mathrm{S}^{0}$ & $\Delta \mathrm{H}^{0}$ \\
$\mathrm{C}_{0}, \mathrm{mg} / \mathrm{L}$ & & $\mathrm{J} / \mathrm{mol} \mathrm{K}$ & $\mathrm{kJ} / \mathrm{mol}$ & $\mathrm{kJ} / \mathrm{mol}$ & & $\mathrm{J} / \mathrm{mol} \mathrm{K}$ & $\mathrm{kJ} / \mathrm{mol}$ \\
& 15 & & 351.27 & 93.125 & 92.011 & $6.8 \times 10^{-19}$ & 351.27 & 93.125 \\
\hline
\end{tabular}

$\Delta H^{\circ}$ and $\Delta G^{\circ}$ can be obtained form the slope and intercept of Van't Hoff plot of $\ln K^{\circ} v s$. $1 / T$ that the data are presented in Table 3. The negative values of $\Delta H^{\circ}$ further confirm the exothermic nature of the adsorption process, while the negative $\Delta S^{\circ}$ values suggest the decrease in adsorbates concentration in solid-liquid interface indicating thereby the increase in adsorbates concentration onto the solid phase. This is the normal consequence of the physical 
adsorption phenomenon, which takes place through electrostatic interactions. In order to further support the assertion that physical adsorption is the predominant mechanism, the values of activation energy $\left(E_{a}\right)$ and sticking probability $\left(S^{*}\right)$ were estimated from the experimental data. They were calculated using a modified Arrhenius type equation related to surface coverage $(\theta)$ as follows ${ }^{35,36}$ :

$$
\mathrm{S}^{*}=(1-\theta) \mathrm{e}^{-(\mathrm{Ea} / \mathrm{RT})} \text {. }
$$

The sticking probability, $S^{*}$, is a function of the adsorbates/adsorbent system under investigation, its value lies in the range $0<S^{*}<1$ and is dependent on the temperature of the system. The parameter $S^{*}$ indicates the measure of the potential of an adsorbates to remain on the adsorbent indefinite. The surface coverage $(\theta)$ can be calculated from the following equation:

$$
\theta=\left[1-\mathrm{C}_{\mathrm{e}} / \mathrm{C}_{\mathrm{o}}\right]
$$

The activation energy and sticking probability were estimated from a plot of $\ln (1-\theta) v s$. $1 / T$. The activation energy, $E_{\mathrm{a}}$, calculated from the slope of the plot was found to be $\mathrm{kJ} / \mathrm{mol}$ for adsorption of CR onto PtN-AC.

\section{Conclusion}

In this study, a platinum nanoparticle loaded on activated carbon was produced and tested as adsorbent for the removal of $\mathrm{CR}$. The effects of $\mathrm{PtN}-\mathrm{AC}$ dosage, initial $\mathrm{pH}$, contact time and initial dye concentration on the removal of $\mathrm{CR}$ were investigated through batch experiments. The optimum dosage, $\mathrm{pH}$ and contact time were obtained to be $0.025 \mathrm{~g}, \mathrm{pH} 4$ and $9 \mathrm{~min}$, respectively.

Isotherm modeling revealed that the Langmuir equation could better describe the adsorption of dye onto the PtN-AC as compared to other models. Kinetic data were appropriately fitted with the pseudo-second-order adsorption rates. The temperature effect is used to calculate the change in activation enthalpy $\left(\Delta H^{0}\right)$, free energy of adsorption $\left(\Delta G^{0}\right)$ and entropy $\left(\Delta S^{0}\right)$. The analysis of these thermodynamic parameters suggests that adsorption is a spontaneous and endothermic.

\section{Acknowledgment}

The authors express their appreciation to the Graduate School and Research Council of the University of Gachsaran Azad University for financial support of this work.

\section{References}

1 Alinsafi A, Khemis M, Pons M N, Leclerc J P, Yaacoubi A, Benhammou A and Nejmeddine A, Chem Eng Process., 2005, 44(4), 461-470.

2 Mohan S V, Roa C N, Prasad K K and Karthikeyan J, Waste Manage., 2002, 22, 575-582.

3 Ozer A, Akkaya G and Turabik M, J Hazard Mater., 2005, 126, 119-127.

4 Ghosh D and Bhattacharyya, KG, Appl Clay Sci., 2002, 20, 295-300.

5 Bulut E, Ozacar M and Şengil I A, J Hazard Mater., 2008, 154, 613-622.

6 Purkait M.K, Maiti A, DasGupta S and De S, J Hazard Mater., 2007, 145(1-2), 287-295.

7 Mall I D, Srivastava V C, Agarwal N K and Mishra I M, Chemosphere, 2005, 61(4), 492-501.

8 Pavan F A, Dias S L P, Lima E C and Benvenutti E V, Dyes Pigments, 2008, 76(1), 64-69.

9 Namasivayam C and Kavitha D, Dyes Pigments, 2002, 54, 47-58.

10 Ghaedi M, Zamani Amirabad S, Marahel F, Nasiri Kokhdan S, Sahraei R and Daneshfar A, Spectrochim Acta Part A: Mol Biomol Spectrosc, 2011, 83, 46-51. 
11 Chatterjee S, Lee D S, Lee M W and Woo S H, Biores. Technol., 100, 2009, 2803-2809.

12 Malik P K and Saha S K, Sep Purif Technol., 2003, 31, 241-250.

13 Vogelpohl A and Kim S M, J Ind Eng Chem., 2004, 10, 33-40.

14 Ciardelli G, Corsi L and Marussi M, Resour Conserv Recycl., 2001, 31, 109-113.

15 Gopinath K P, Murugesan S, Abraham J, Muthukumar K and Bacillus S P, Bioresour Technol., 2009, 100, 6295-6300.

16 Orfao J J M, Silva A I M, Pereira J C V, Barata S A, Fonseca I M, Faria P C C and Pereira M F R, J Coll Interf Sci., 2006, 296(2), 480-489.

17 Nandi B K, Goswami A and Purkait M K, J Hazard Mater., 2009, 161(1), 387-395.

18 Slejko F L, Adsorption Technology, New York, 1985.

19 Suffet I H and McGurie M J, Ann Arbor Sci Michigan, 1985, 1-2.

20 Jain R and Sikarwar S, J Hazard Mater., 2008, 152, 942-948.

21 Ghaedi M, Hassanzadeh A and Nasiri Kokhdan S, J Chem Eng., 2011, 56, 2511-2520.

22 Geng X, Zhang H, Ma Y and Zhong H, J Power Sources, 2010, 195, 1583.

23 Nandi B K, Goswami A and Purkait M K, J Hazard Mater., 2009, 161(1), 387.

24 Smiciklas I D, Milonjic S K, Pfendt P and Raicevic S, Sep Purif Technol., 2000, 18(3), 185-194.

25 Guendi M E, Adsorption Sci Technol., 1991, 8, 217-225.

26 Hameed B H, Ahmad A L and Latiff K N A., Dyes and Pigments, 2007, 75(1), 143-149.

27 Langmuir I J, Am Chem Soc., 1916, 38, 2221.

28 Freundlich H M F, Zeit Phys Chem (Leipzig)., 1906, 57, 385-470.

29 Temkin M.J and Pyzhev V, Acta Physiochim. USSR, 1940, 12, 217-222.

30 Ho Y S, McKay G, Wase D A J and Foster C F, Adsorption Sci Technol., 2000, 18(7), 639-650.

31 Amin N K, J Hazard Mater., 2009, 165(1-3), 52-62.

32 Basar C A, J Hazard Mater., 2006, 135, 232-241.

33 Chatterjee S, Chatterjee S, Chatterjee B P and Guha A K, Colloids Surf., 2007, 299, 146-152.

34 McKay G, Chem Eng J., 1983, 27, 187.

35 Kannan K and Sundaram M M, Dyes Pigments, 2001, 51, 25-40.

36 Jnr M H and Spiff A I, Electron J Biotechnol., 2005, 8, 162-169. 


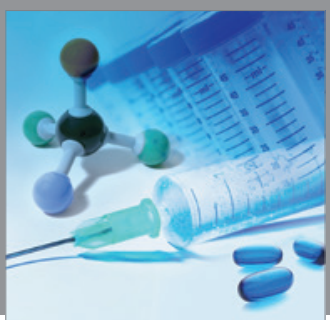

International Journal of

Medicinal Chemistry

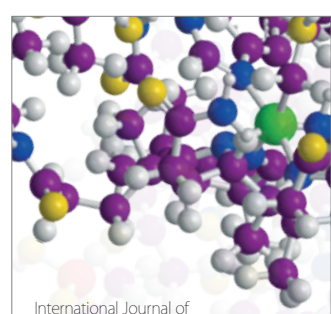

Carbohydrate Chemistry

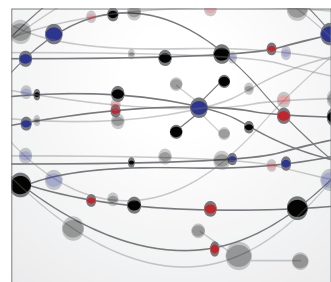

The Scientific World Journal
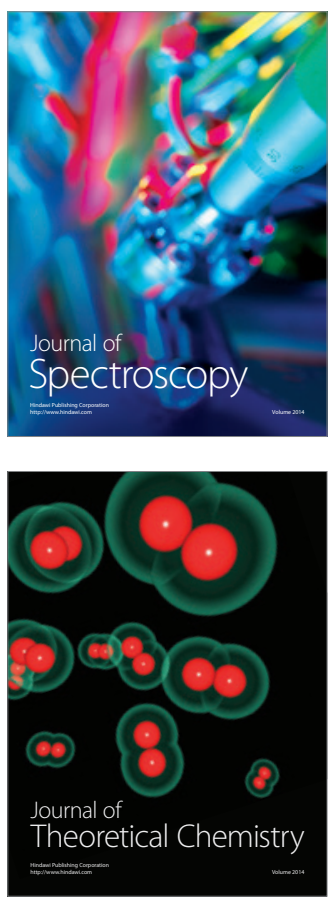
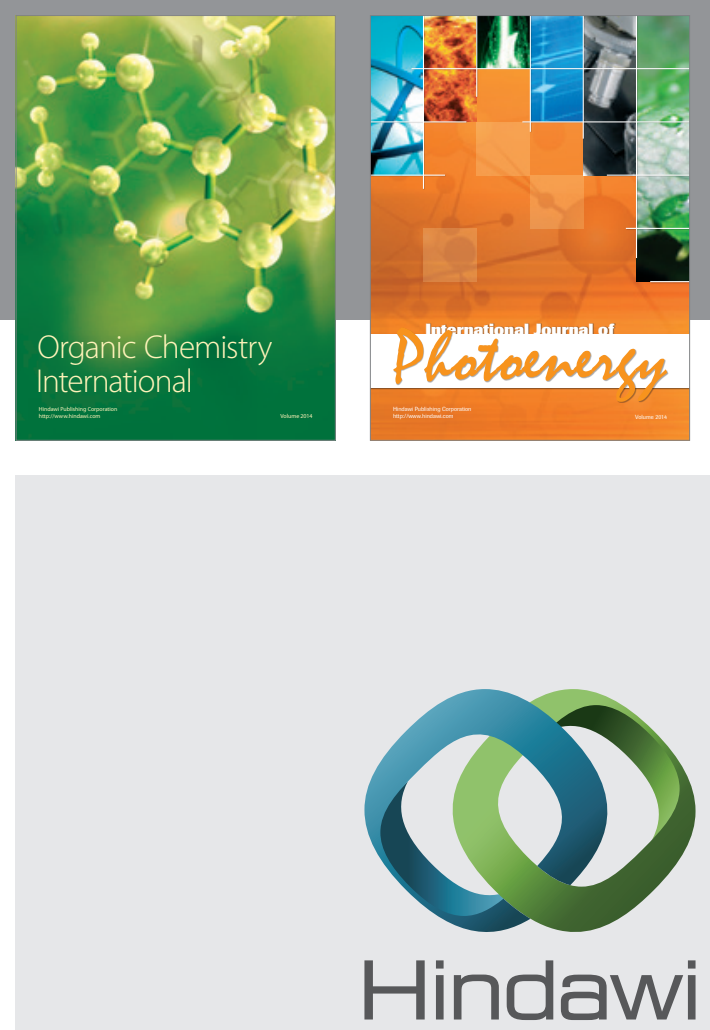

Submit your manuscripts at

http://www.hindawi.com
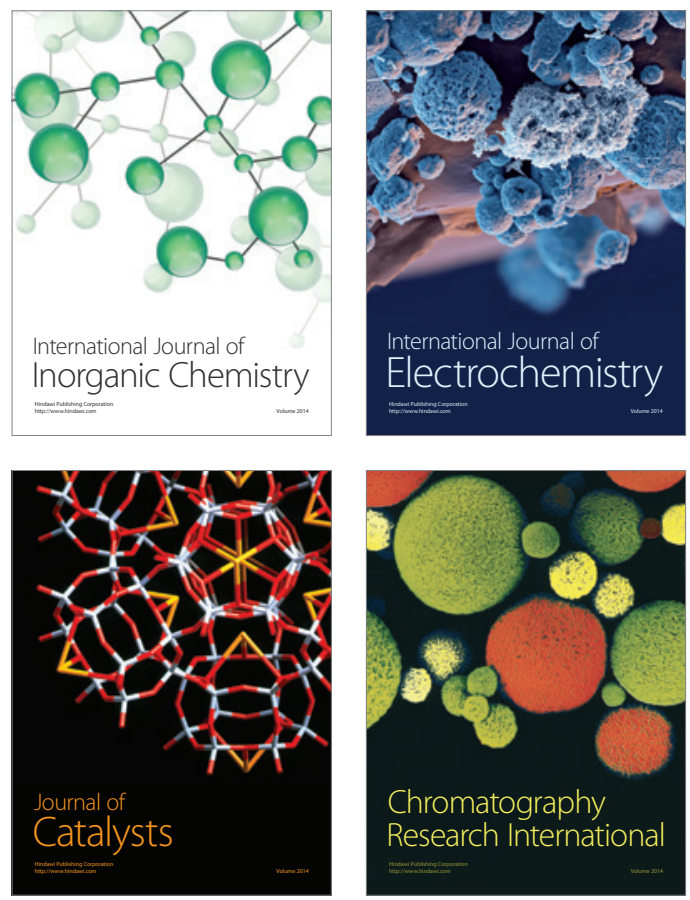
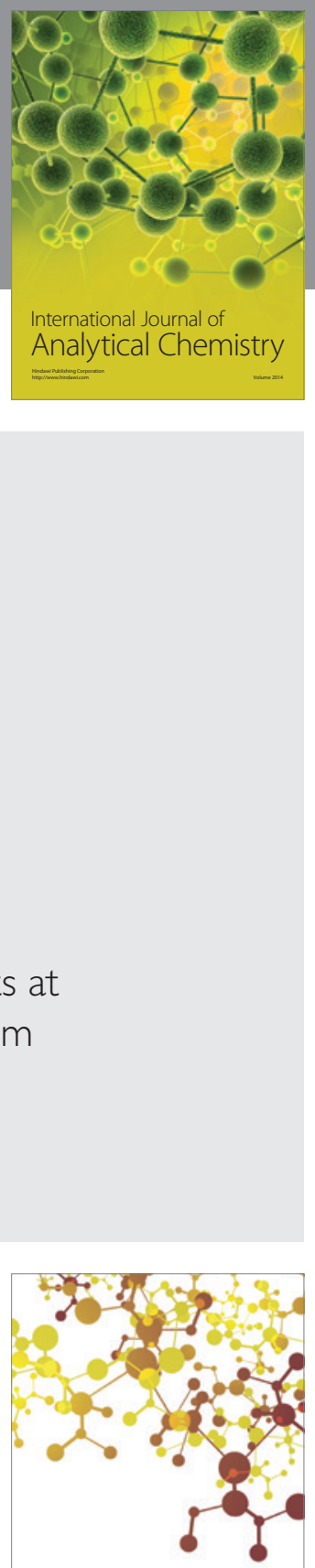

Journal of

Applied Chemistry
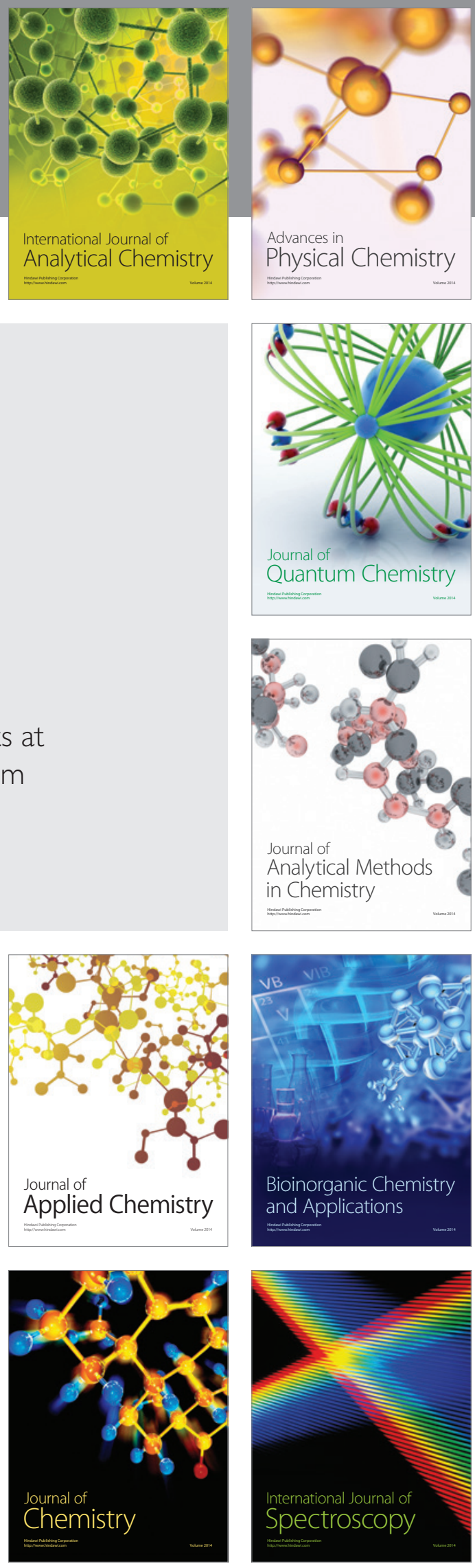